\title{
Algumas Razões para leVar a SÉrio a Metaindução Pessimista
}

\author{
Tiago Luís TeiXeira de Oliveira
}

\begin{abstract}
The present paper aims to give an account of pessimistic meta-induction (PMI) and reply to some representative realist authors who want to consider PMI a fallacy. Most of that accounts are misinterpretations of Laudant's ideas and fails the target. This work intend that PMI is neither a induction nor a reductio, but a skeptic challenge. If this is right then PMI could not be a fallacy and the realism cannot escape from the task of explain why the success is a good indication for the truthlikeness of the current theories.
\end{abstract}

Keywords: Pessimistic induction; realism; anti-realism; Laudan; Psillos.

\section{Introdução}

Um debate caloroso tem sido travado na filosofia da ciência sobre como devemos interpretar as teorias científicas. A grande disputa nesse sentido é sobre o caráter ontológico que acompanha toda teorização, por mais econômica que esta seja ao introduzir termos que no nosso tratamento ordinário supostamente refeririam a entidades inobserváveis. Quando uma teoria bem sucedida lança mão de 'elétrons', 'fótons', 'antipartículas' e outros termos cuja existência não pode ser intuída de uma observação simples, ou mesmo de uma observação no microscópio, deveríamos crer que essas entidades são partes constituintes da realidade ou deveríamos simplesmente considerá-las metodologicamente úteis sem comprometermos com sua existência? Basicamente, é esse o problema que divide realistas e antirrealistas. Reparemos que o problema filosófico não é saber como os cientistas se posicionam, ou como eles agem de fato. ${ }^{1}$ Mas se há razões para crer que os termos teóricos são referenciais ou não.

O realista entende que as teorias maduras e bem sucedidas são aproximadamente verdadeiras na sua descrição do mundo observável e inobservável. O principal argumento do realismo científico veio de Hilary Putnam, segundo o qual a postura realista "é a única filosofia que não faz do sucesso da ciência um milagre" (Putnam 1975, p.73). Dentre as explicações possíveis para o sucesso da ciência, a mais promissora parece ser a de que as teorias são (aproximadamente) verdadeiras, descrevendo o mundo tal como ele deve ser realmente. O argumento, também chamado de argumento sem milagre (NMA) é uma forma de inferência pela melhor explicação (IBE), também conhecido pelo nome de abdução. ${ }^{2}$

Principia 18(2): 269-290 (2014).

Published by NEL — Epistemology and Logic Research Group, Federal University of Santa Catarina (UFSC), Brazil. 
Do lado antirrealista há um ceticismo sobre a existência das entidades postuladas teoricamente. Os positivistas lógicos, por exemplo, assumiam-se instrumentalistas, ou seja, que os termos teóricos ocupavam meramente um papel metodológico, na medida em que consequências observáveis das teorias eram verificadas empiricamente. Isso não significaria, porém, que os termos teóricos são referentes a uma realidade inobservável. ${ }^{3}$ A necessidade de distinção teórico/observacional pressuposta no instrumentalismo e a evidente inconsistência entre o método verificacionista e a filosofia da ciência de cunho positivista (que não é verificável) contribuíram para que essa corrente perdesse espaço para as filosofias realistas. O panorama só vai se transformar com a publicação de The scientific image (1980), por Van Fraasen. O autor desenvolveu uma filosofia conhecida pelo nome de empirismo construtivo na qual procura substituir o problemático par teórico/observável pelo par observável/inobservável. Van Fraasen realizou severas críticas ao uso da IBE que sustenta o realismo. Sua ideia é a de que a ciência pode ser entendida como uma competição na qual as teorias mais adequadas permanecem. Essa visão darwinista da ciência dispensa o NMA pois reconhece que para um certo número de teorias bem sucedidas há outro tanto de teorias que falharam. Várias outras propostas antirrealistas alternativas se seguiram ao empirismo construtivo e, como o objetivo deste texto não é mais do que esclarecer o status da discussão para a compreensão e os desdobramentos do conceito de metaindução pessimista, não nos prolongaremos nas outras propostas.

Diferentemente de Van Fraasen, que formulou uma filosofia alternativa ao realismo científico dominante, Larry Laudan avançou outra crítica poderosa ao NMA, lançando dúvidas sobre a relação necessária entre sucesso, verdade e referência. Trata-se do artigo intitulado A confutation of convergent realism (1980). Laudan introduziu um desafio baseado na história das mudanças teóricas que posteriormente ficou conhecido como metaindução pessimista ou simplesmente indução pessimista (PMI). Segundo o filósofo, supor que as teorias sejam verdadeiras por serem bem sucedidas é desconsiderar que muitas teorias empiricamente bem suportadas ao longo da história foram substituídas por outras e, com isso, as entidades introduzidas pelas teorias anteriores foram consideradas fictícias na nova ontologia da teoria que a sucedeu. Por uma metaindução pessimista poderíamos supor que nossas melhores teorias atuais estão sujeitas ao mesmo destino. Assim como ocorreu com o argumento de Putnam, várias objeções são levantadas contra a indução pessimista formulada por Laudan.

Nosso objetivo aqui é expor sinteticamente a PMI de Laudan, analisar algumas críticas realistas e argumentar contra tais respostas, mostrando que elas falham o alvo. Os filósofos que procuraram minar a indução pessimista formalizando-a e considerando-a falaciosa cometeram um erro ingênuo: apesar do nome atribuído à ideia de Laudan, a metaindução pessimista como exposta no artigo de 1981 não é um argumento, mas um desafio cético, devolvendo o ônus da prova aos realistas. 


\section{O que é metaindução pessimista}

Alguns autores traçam a origem da PMI em Poincaré (1902/1950, p. 160), o qual afirmava que se olharmos para a história da ciência "preveremos que as teorias em voga hoje vão ... sucumbir ao seu tempo" e Putnam (1978, p.25) cujo argumento da "indução desastrosa" pode ser reformulado tal como apresenta Lewis (2001, p.372):

P1: Assumamos que a maioria das teorias científicas atuais é verdadeira.

P2: Então a maioria das teorias científicas passadas é falsa, uma vez que diferem de modo significativo das teorias científicas atuais.

C: Logo, por uma indução sobre as teorias passadas, a maioria das teorias atuais é provavelmente falsa.

Muitos autores, com razão, não dão atenção ao argumento como exposto acima. ${ }^{4}$ Parece bem mais consensual que foi Larry Laudan quem propôs um desafio realmente problemático para um realismo epistêmico que assume nossas teorias de maior sucesso como aproximadamente verdadeiras. No artigo de 1981 (p.21-22), Laudan analisa o realismo epistêmico convergente (CER), entendendo-o como uma posição na qual

R1) As teorias maduras são aproximadamente verdadeiras e mais próximas da verdade do que as antecessoras

R2) Os termos teóricos e observacionais dessas teorias genuinamente referem

R3) Teorias sucessivas nas ciências maduras são deste tipo

R4) Novas teorias precisam explicar o sucesso das antecessoras.

R5) Teorias de ciências maduras devem ser empiricamente bem sucedidas

Segundo o filósofo, a sustentação da posição realista repousa quase que exclusivamente na adequação empírica (R5), já que a melhor explicação para o sucesso da ciência (entendida aqui como adequação empírica e alto poder explicativo e preditivo) seria a verdade aproximada das teorias atuais. O realismo espera que, por meio dessa IBE, fique estabelecida a maior probabilidade de uma teoria ser verdadeira quando bem sucedida empiricamente:

Tomando o sucesso de teorias presentes e passadas como dado, proponentes do CER assumem que se CER fosse verdadeiro, se seguiria que o sucesso e o sucesso progressivo da ciência viriam naturalmente. Igualmente, eles alegam que se CER fosse falso, o sucesso da ciência seria 'miraculoso' e sem explicação (Laudan 1981, p.22)

A estratégia de Laudan no artigo é mostrar que a relação entre sucesso, referência e verdade não se dá naturalmente como querem os realistas. Para o propósito da 
argumentação que demonstra que sucesso empírico não é nem condição suficiente, nem necessária para uma teoria ser referencial, Laudan mencionou casos históricos em que reconhecemos $(a)$ teorias com termos referenciais embora empiricamente fracassadas e $(b)$ teorias com termos não referenciais embora bem sucedidas. ${ }^{5}$

Exemplos que corroboram $(a)$ seriam as várias teorias atômicas que precederam as atuais. O termo 'átomo' é indiscutivelmente referencial de acordo com nosso conhecimento atual embora os modelos atômicos obsoletos tenham falhado em realizar previsões bem sucedidas e explicações aceitáveis. Na verdade, como ressalta Laudan, é extremamente fácil criar teorias genuinamente referenciais e massivamente falsas. Se podemos fazer isso com hipóteses envolvendo entidades observáveis (ex: o modelo geocêntrico de Ptolomeu), muito mais é possível em relação a termos teóricos cuja referência, a princípio, não pode ser verificada a olho nu. Talvez algum realista convergente diria que a substituição das teorias antigas por hipóteses melhores foi um passo em direção a uma teoria mais próxima da verdade, o que é atestado pela preservação dos termos referenciais e pela melhor adequação empírica da nova teoria. Mas a simples existência de uma teoria genuinamente referencial embora hoje indiscutivelmente falsa levanta dúvidas se o sucesso empírico é condição necessária para uma teoria genuinamente referencial.

O caso é que também teorias bem sucedidas são substituídas e, ao contrário do que foi discutido nos exemplos anteriores, os termos teóricos das teorias abandonadas passam a ser considerados não referentes. Uma lista de exemplos favorece $(b)$ :

- as esferas cristalinas da astronomia antiga e medieval;

- a teoria dos humores da medicina;

- a teoria dos eflúvios da eletricidade estática;

- a geologia catastrofista com seu comprometimento com o dilúvio universal (de Noé);

- a teoria do flogisto da química;

- a teoria do calórico;

- as teorias da força vital da fisiologia;

- o éter eletromagnético;

- o éter óptico;

- a teoria da inércia circular;

- teorias da geração espontânea. (Laudan 1981, p.33)

Para ficarmos somente em um caso, consideremos o sucesso explicativo que as teorias do éter tiveram antes de serem substituídas por teorias que dispensavam a entidade: o éter óptico explicava a reflexão, a difração, interferência, dupla refração, 
difração e polarização, além do que permitia fazer algumas previsões. É um perfeito caso de teoria bem sucedida. O que se segue da história de teorias como as que foram acima mencionadas é que nem teorias referentes são necessariamente bem sucedidas nem teorias bem sucedidas (em sua época) são necessariamente referentes (segundo as teorias atuais).

A questão da verdade é um pouco mais problemática devido, segundo Laudan, à vagueza do conceito de 'aproximadamente verdadeiro'. Uma boa parte dos realistas evita uma afirmação categórica de que tal ou tal teoria é totalmente verdadeira no sentido tarskiano, contentando-se com a tese de que nossas teorias atuais estão mais próximas de uma descrição do mundo observável e inobservável do que as antecessoras. Mas se o significado de 'aproximadamente verdadeiro' implica, como parece, que uma parte das nossas melhores teorias é falsa, temos o problema de responder que porção teórica não corresponde à realidade e que termos são genuinamente referenciais. Os realistas que apelam para verossimilhança ou para uma verdade aproximada encontram dificuldades semânticas e epistêmicas, já que não possuem uma boa concepção de verossimilhança que implique sucesso empírico e nem um critério epistêmico que garanta que uma teoria é aproximadamente verdadeira:

\begin{abstract}
Mesmo se o realista tivesse uma caracterização semanticamente adequada de verdade aproximada ou parcial, e mesmo se tal semântica implicasse que a maior parte das consequências de uma teoria aproximadamente verdadeira seria verdadeira, ele ainda estaria sem qualquer critério que garantisse epistemicamente a designação de aproximadamente verdadeira a uma teoria. Assim, o realista parece ser cheio de intuições e vazio tanto de uma semântica quanto de uma epistemologia do aproximadamente verdadeiro. (Laudan 1981, p.32 grifos do autor)
\end{abstract}

O que se percebe, por essa breve apresentação, é que Laudan lança dúvida sobre a capacidade de os realistas provarem sua tese tanto recorrendo à noção de verossimilhança quanto lançando mão do critério epistêmico de adequação empírica. Veremos, a seguir, como alguns autores procuraram refutar a PMI.

\title{
2. Sobre as críticas à metaindução pessimista (PMI)
}

Consideraremos aqui as oposições de Park (2011), Lewis (2001), Mizrahi (2012) e Psillos (1996) à PMI, devido à diversidade das estratégias de cada autor. Não seria possível analisar aqui todas as respostas realistas existentes. Pensamos que esses quatro filósofos podem constituir numa boa amostra do modo como a PMI tem sido contestada pelo realismo convergente.

Principia 18(2): 269-290 (2014). 


\subsection{Indução otimista}

Park no seu A confutation of the pessimistic induction (2011, p.76) reformula o que considera ser a posição de Laudan da seguinte maneira:

(1) Teorias bem sucedidas do passado são completamente falsas

(2) Logo, as teorias bem sucedidas atualmente são completamente falsas.

Embora já de partida seja possível sustentar que Park cometa uma falácia do espantalho, ${ }^{6}$ sua posição ao longo do artigo não depende tanto desse erro, sustentando-se no que seriam diferenças consideráveis entre teorias do presente e teorias passadas. Segundo Park as teorias do passado a que Laudan se refere são anteriores ao século XX e não contavam com o aparato atual de interdependência (que ele chamou de neighbor constraints). No entender do crítico de Laudan, as teorias desenvolvidas a partir do século XX não são construídas isoladamente, desconsiderando outros estudos de áreas afins do saber. Essa consistência entre disciplinas distintas que tende para a unificação do conhecimento científico não era uma realidade no século XIX, o que faz com que Park acredite que as teorias atuais são mais próximas da verdade do que as antecessoras:

A unificação da ciência que ocorreu no fim do século dezenove e no início do século vinte parece ser a força guia que facilitou as restrições vizinhas (neighbor constraints). A ciência do século vinte e adiante nos dá uma visão bem mais unificada do mundo do que a ciência do século dezenove. (Park 2010, p.86)

$\mathrm{O}$ argumento de Park acaba defendendo uma premissa que outras formulações da PMI (como a que veremos em Lewis/Mizrahi/Psillos adiante) atacam: a de que as teorias do passado diferem das teorias atuais de modo significativo.

Além do mais, o artigo de Park apela para o que seria uma indução otimista, uma constatação de que a famigerada lista de Laudan não representa a maioria das teorias do passado, mas apenas algumas cujos termos não são referentes à luz das teorias atuais. Nessa sutil diferença (entre algumas e a maioria) é possível apelar para as teorias que continuaram referentes à luz das teorias atuais e daí, por indução supor que as teorias atuais são referentes:

Não é tarefa difícil construir a indução otimista. Para cada teoria substituída na lista de Laudan, há uma teoria substituta correspondente cujo termo central refere. Por exemplo, para a teoria ptolomaica, há a teoria copernicana, para a teoria do flogisto, a teoria do oxigênio, para a teoria do calórico, a teoria cinética e assim vai. Os termos chave das teorias substitutas referem à luz das teorias atuais. As teorias substitutas são claramente teorias do passado pois houve períodos nos quais elas competiam com as substituídas. Então, por exemplo, se a teoria do calórico é uma teoria passada, igualmente a teoria cinética. (Park 2010, p.78)

Principia 18(2): 269-290 (2014). 
Park parece estar dando um passo imprudente: o simples reconhecimento de que há termos teóricos que permanecem diante das mais bem sucedidas teorias atuais não implica que tais termos são referentes e nem que as atuais teorias são verdadeiras. Seria como supor que uma teoria é verdadeira por não ter sido refutada. A consistência, ou restrições vizinhas (neighbor constraints), ou coerência é o mínimo que se pode exigir de cientistas realistas pois obviamente acreditam que as teorias atuais sejam aproximadamente verdadeiras. Mas a mesma crítica que se aplica a qualquer teoria coerentista da verdade ${ }^{7}$ pode ser feita a um corpo coerente de teorias científicas: teorias falsas podem ser coerentes entre si, o que permite afirmar que embora a coerência entre teorias seja condição necessária para que todas as teorias envolvidas sejam verdadeiras, não é uma condição suficiente. Suponha-se que uma ou mais teorias atualmente aceitas sejam falsas, com pelo menos um termo não referente. A inexistência de uma teoria substituta que prescinda da "entidade fictícia" faz com que as teorias construídas coerentemente com a teoria falsa sejam também passíveis de falsidade e uso de termos não referentes. Aliás, como já citamos em outro lugar a respeito de Feyerabend, a consistência pode ser uma exigência conservadora que impede avanços mais radicais no conhecimento científico, especialmente nos casos em que há subdeterminação. ${ }^{8}$

\section{2. $\mathrm{O}$ falso positivo}

Lewis (2001) fez uma crítica bem mais elaborada, supondo que Laudan tenha arrolado um argumento por reductio ad absurdum. O argumento confessadamente inspirado em Psillos (1996) é o seguinte:

$\left(1^{\prime}\right)$ Assumindo que o sucesso de uma teoria é um teste confiável para sua verdade.

$\left(2^{\prime}\right)$ A maioria das atuais teorias científicas é bem sucedida.

$\left(3^{\prime}\right)$ Então, a maioria das teorias atuais é verdadeira.

$\left(4^{\prime}\right)$ Assim a maioria das teorias passadas é falsa, uma vez que diferem das teorias atuais de modo significativo.

$\left(5^{\prime}\right)$ Muitas dessas teorias passadas foram bem sucedidas.

(6') Então o sucesso de uma teoria não é um teste confiável para sua verdade. (p.373)

O nosso segundo crítico da PMI procura mostrar que os casos de termos não referentes de teorias bem sucedidas apontados por Laudan são casos de falso positivo, o que tornaria parcialmente falsa a premissa $\left(5^{\prime}\right)$. De acordo com Lewis, é possível mostrar que os casos de falso positivo (teorias falsas bem sucedidas) e os casos de falso negativo (teorias verdadeiras mal sucedidas) são explicados pela probabilidade. Os realistas, pensa Lewis, querem afirmar que as taxas de falsos positivos e 
falsos negativos são baixas, o que permite deduzir que o sucesso empírico seria um indicativo confiável da verdade de uma teoria.

Assumindo que a $P(T)$ seja a probabilidade de uma teoria ser verdadeira e $P(S)$ a probabilidade de uma teoria ser bem sucedida, e que $p$ seja a proporção de falsos positivos enquanto $q$ de falsos negativos, temos que:

$$
p=P(\neg T \cdot S) / P(\neg T) \text { e } q=P(T \cdot \neg S) / P(T) .
$$

Daí deduz-se que

$$
P(S)=(1-p-q) P(T)+p .
$$

Sabendo que $P(T)=1 / 2$, substituindo na equação acima temos que

$$
P(S)=(1+p-q) / 2 \text {. }
$$

Para que a maioria das teorias seja verdadeira é preciso que $P(T)>1 / 2$. Condição que é preenchida quando $P(S)>(1+p-q) / 2$.

Assumindo taxas baixas de $p$ e $q$ teríamos um valor de $P(S)$ bastante próximo de $1 / 2$. Neste caso teríamos razões suficientes para ligar a probabilidade de sucesso à probabilidade de uma teoria ser verdadeira. Um argumento que recorra à história como é o caso da PMI precisaria, de acordo com Lewis, provar que ou as taxas de $p$ ou as de $q$ são altas.

Lewis espera que, por analogia a casos aplicáveis do paradoxo do falso positivo seja possível minimizar a força dos exemplos históricos de Laudan e ainda explicar a afirmação de que "para cada teoria altamente bem sucedida no passado da ciência que agora acreditamos ser uma teoria genuinamente referente, alguém pode encontrar meia dúzia de teorias uma vez bem sucedidas que agora consideramos substancialmente não referentes" (Laudan 1981, p.35). O paradoxo ao qual Lewis refere-se é o que constatamos, por exemplo, no caso de uma doença rara, cujo diagnóstico seja altamente confiável. Como a doença é rara, o número de pessoas aleatoriamente escolhidas numa população diagnosticadas com um falso positivo será maior do que o número de pessoas escolhidas nesse mesmo processo portadoras de tal doença. Pode-se supor, analogamente que o número de teorias verdadeiras seja relativamente pequeno em relação ao número de teorias falsas e que há a mesma chance de um falso positivo e de um falso negativo. Lewis chega a mostrar que se há 1 teoria verdadeira para cada 25 teorias e uma taxa de 1 falso (tanto positivo quanto negativo) para cada 5 testes, a chance de um falso positivo é seis vezes maior do que de uma teoria verdadeira e bem sucedida. O produto $1 / 25$ (taxa de teorias verdadeiras) $\times 4 / 5$ (taxa de confiabilidade do teste) dá 4/125. Já os falso positivos seriam 24/25 (taxa de teorias falsas) $\times 1 / 5$ (chance de falso positivo) ou seja, 24/125. Exatamente 1 teoria referente e bem sucedida para 6 teorias bem sucedidas mas não referentes.

Principia 18(2): 269-290 (2014). 
O artigo de Lewis quer, dessa forma, provar que meros contraexemplos históricos de teorias não referentes e bem sucedidas não minam a crença realista de que as teorias atuais são mais próximas da verdade do que as teorias passadas:

Então o fato de que teorias falsas bem sucedidas ultrapassam o número de teorias verdadeiras em algum momento não demole a confiabilidade do sucesso como teste para a verdade naquele momento, nem em outros momentos. Em outras palavras, o realista pode interpretar os casos históricos de Laudan não como evidência contra a confiabilidade do sucesso como teste para a verdade, mas meramente como evidência da escassez de teorias verdadeiras no passado. (Lewis 2001, p.337)

É preciso reconhecer que o posicionamento lewisiano apresenta uma explicação coerente entre o realismo e os casos de sucesso temporário de uma teoria falsa. Mas aqui vale a pena lembrar que quem assume o sucesso como indicativo da verdade de uma teoria é o realista, como ocorre no NMA. O autor quer supor que a PMI de Laudan seja um argumento falacioso porque o desafio antirrealista baseado em casos históricos (na forma de uma reductio) não forneceu uma quantidade de teorias falsas dentre as quais muitas seriam bem sucedidas. Lewis supõe que esse é um trabalho considerável ainda por se fazer e, caso fosse demonstrada a alta taxa de falsos positivos, o posicionamento do realista convergente estaria comprometido. Suponho que aqui Lewis inverte o ônus da prova. O realista é que deve demonstrar que os casos de falso positivos são pequenos, afinal, todo o aparato probabilístico do artigo de Lewis funciona na hipótese de ser o sucesso um bom indicativo da verdade de uma teoria. Mas como é justamente a relação estreita entre sucesso e verdade que o realista quer provar, Lewis parece cometer uma petição de princípio. O argumento de Lewis poderia se apresentado da seguinte forma:

$\left(1^{\prime \prime}\right)$ Se o sucesso é bom indicativo da verdade das teorias científicas então as taxas de falso positivo são baixas.

$\left(2^{\prime \prime}\right)$ Se as taxas de falso positivo forem baixas então pode-se explicar realisticamente a existência de teorias falsas bem-sucedidas ao longo da história.

$\left(3^{\prime \prime}\right)$ Pode-se explicar realisticamente a existência de teorias falsas bem-sucedidas.

$\left(4^{\prime \prime}\right)$ O sucesso é bom indicador da verdade das teorias (e as taxas de falso positivo são baixas).

Repare-se que o realista pretende em última instância provar $\left(4^{\prime \prime}\right)$ e, se Lewis o faz, ele o faz por IBE. Mas o filósofo não deixa muito claro como a explicação que recorre ao "falso positivo" é a melhor explicação para a existência de teorias falsas bem-sucedidas. Alguém poderia ainda afirmar que basta $\left(3^{\prime \prime}\right)$ para rejeitar a PMI de Laudan. Ainda que se conceda esse ponto, para que $\left(3^{\prime \prime}\right)$ decorra como 
uma inferência dedutiva seria preciso assumir ( $\left.4^{\prime \prime}\right)$ como premissa, donde percebese claramente a circularidade do argumento de Lewis. Por essa razão mencionamos a inversão da prova. É o realista que precisa mostrar taxas baixas de falso positivo para recusar o desafio antirrealista.

Há uma outra crítica a Lewis, um pouco mais geral no contexto do debate entre PMI e NMA, dirigida por Saatsi (2005). Saatsi observa que a tese do falso positivo de Lewis supõe, embora não mencione, um tipo de teoria científica que não parece fazer o menor sentido: o que seriam as teorias ao mesmo tempo falsas e mal sucedidas? Sem um grande domínio desse tipo de teoria (falsa e mal sucedida) não é possível desenvolver o argumento probabilístico que atribui uma taxa baixa de falso positivos, respondendo ao PMI. Mas se esse tipo de teoria for em número elevado, o próprio NMA perde sua força:

Mas o que são exatamente as teorias que não são bem sucedidas e nem verdadeiras? Devemos contar somente as propostas teóricas feitas por cientistas eminentes, ou talvez todas as propostas atualmente publicadas em periódicos científicos, ou o que? É fácil imaginar uma variedade de fatores sociológicos, digamos, números complacentes de teorias falsas e mal sucedidas, diretamente afetando a noção de confiabilidade em causa. Mas por que devemos nos preocupar com aquelas teorias? Simplesmente parece que o debate entre NMA e PMI não envolve teorias falsas e mal sucedidas (ou verdadeiras ainda que mal sucedidas, para tal matéria) em nada parecido com o caminho que Lewis projeta. (Saatsi 2005, p.1096)

Para que o realismo de Lewis proceda, a melhor explicação para o sucesso das melhores teorias atuais é que ou as teorias são verdadeiras ou são uma pequena parcela bem sucedida de um enorme domínio de teorias falsas. É fácil perceber que, para acomodar a PMI, Lewis compromete a ideia de que a atividade científica é extremamente bem sucedida de modo que só o realismo não torna tal sucesso um milagre. Ainda que faça algum sentido falar de teorias falsas e mal sucedidas, o realismo lewisiano está dando razão à visão do empirismo construtivo de Van Fraasen (1980), segundo o qual a história da ciência é de fracasso mais do que sucesso, num tipo de competição análogo ao observado por Darwin no universo dos seres vivos. Nesse caso, NMA deixaria de ser uma aposta competitiva para o realismo.

\subsection{Um mau argumento?}

Recentemente Mizrahi (2013) analisou a PMI sugerindo que a mesma não passa de um mau argumento que já foi longe demais (o título do artigo era justamente esse: The pessimistic induction: a bad argument gone too far). Mizrahi procura mostrar que a formulação da PMI como reductio é inválida e que a formulação da mesma como uma indução é fraca. Neste texto não me concentrarei na versão da PMI como

Principia 18(2): 269-290 (2014). 
indução. A razão para isso é bastante semelhante ao que já fora dito sobre Park em 2.1: a mera enumeração de casos passados de teorias bem sucedidas não referenciais não permite uma generalização de que as teorias atuais são provavelmente falsas.

Não há, igualmente, grandes novidades na análise da PMI como reductio. $\mathrm{O}$ autor retoma a formulação de Lewis já exposta neste texto (parte 2.2) e a reformula em vários sentidos para os quais a premissa $\left(4^{\prime}\right)$ - de que as teorias do passado diferem-se substancialmente das teorias atuais - desempenha um papel relevante para afirmar ao menos a probabilidade de as teorias passadas serem falsas. Mizrahi supõe que o pessimista pensa da seguinte forma (p.3211):

$\left(1^{\prime \prime \prime}\right)$ A maioria das teorias presentes são verdadeiras

$\left(2^{\prime \prime \prime}\right)$ A maioria das teorias passadas diferem-se das atuais de modo significativo

$\left(3^{\prime \prime \prime}\right)$ Logo a maioria das teorias passadas são falsas

Todas as reformulações do argumento acima por Mirzrahi seguem basicamente mostrando que a falsidade (ou diferença do valor de verdade, ou provável falsidade) das teorias passadas é um non sequitur das duas premissas anteriores. Não pretendo contestar aqui a declaração de Mirzrahi sobre o argumento explicitado, pois penso que é irrelevante para o desafio que a PMI lança ao realista. Laudan não provou que boa parte das teorias passadas eram falsas, nem mesmo que a maioria das teorias o eram, nem seria necessário. Laudan apenas contestou a ligação entre sucesso e verdade, especificamente nos casos de teorias bem-sucedidas que postulavam entidades hoje consideradas fictícias à luz das teorias atuais. A menos que o realista consiga provar que teorias não referentes podem ser aproximadamente verdadeiras à luz das teorias atuais (o que Psillos tentará, como veremos adiante) ou que as teorias listadas por Laudan não eram casos de sucesso, o CER ainda encontra-se desafiado a mostrar como o sucesso é indicador de verdade.

Talvez uma reformulação da reductio mais condizente com o artigo de Laudan teria a seguinte estrutura:

$\left(1^{\prime \prime \prime \prime}\right)$ Teorias com entidades não referentes são falsas.

$\left(2^{\prime \prime \prime \prime}\right)$ As teorias de sucesso atuais são verdadeiras.

$\left(3^{\prime \prime \prime \prime}\right)$ Segundo as teorias de sucesso atuais, algumas teorias passadas de sucesso continham entidades não referentes.

$\left(4^{\prime \prime \prime \prime}\right)$ Logo, segundo as teorias atuais, algumas teorias passadas de sucesso são falsas.

O argumento acima não pode ser considerado um non sequitur e preserva, segundo penso, a essência da PMI de Laudan (embora eu precise reiterar que não considero que Laudan proponha nem uma indução e nem uma reductio, mas um desafio 
cético). A adição de uma premissa condicional (se o sucesso fosse bom indicador de verdade aproximada, não haveria teorias ao mesmo tempo falsas e bem-sucedidas) levaria à conclusão antirrealista de que o sucesso não é necessariamente indicador de verdade.

Além do mais, tenho sérias dúvidas de que a PMI de Laudan realmente dependa de $\left(2^{\prime \prime \prime} / 4^{\prime \prime}\right)$. A tese de que as teorias do passado se diferem significativamente das teorias atuais é um dos pontos mais contestados por realistas como Mizrahi e Lewis. Park, ao contrário, esperava que a diferença entre teorias passadas e presentes fosse suficiente para recusar que estamos hoje diante de teorias com a mesma probabilidade de serem não referentes tal como eram as teorias da lista de Laudan. A preocupação de Park é compreensível, pois se a PMI oferece algum perigo para o realismo é porque, sendo as teorias atuais não muito diferentes das teorias já substituídas (todas bem-sucedidas), o mesmo que hoje se diz das teorias passadas pode ser dito das teorias correntes: que não há garantias de que as teorias correntes sejam referentes apesar do sucesso empírico. Ou, em outras palavras, assim como no passado o sucesso não garantiu a verdade das teorias, [dada a semelhança com as atuais teorias] no presente não podemos supor a verdade das teorias somente por serem bem-sucedidas.

O grande problema posto pela PMI é o de exigir do realista uma prova de que o sucesso de uma teoria é um indicador confiável para a verdade aproximada da mesma e (um passo importante que, com a exceção de Psillos, vem sendo negligenciado pelos realistas aqui citados) uma teoria da referência que permita esclarecer o que quer dizer "aproximadamente verdadeiro". Só com uma teoria satisfatória da referência seria possível afirmar que as teorias atuais são mais verossímeis que as do passado e que as teorias passadas eram, também elas, aproximadamente verdadeiras.

\section{4. 'Divide et Impera'}

Provavelmente a resposta realista mais promissora contra a PMI fora dada por Psillos no artigo Scientific realism and 'pessimistic induction' (1996). Psillos prefere um caminho mais prudente e trabalhoso do que os autores realistas mencionados aqui: no lugar de procurar minar a PMI como um argumento falacioso e inócuo ao realismo convergente, o filósofo sugere que é o realismo que precisa se adaptar à PMI.

A estratégia de Psillos é chamada de divide et impera em clara referência à conhecida manobra política de quebrar poderes concentrados em partes menores, mais fáceis de controlar. O filósofo entende ser possível mostrar que as substituições de teorias ao longo da história preservaram a verdade aproximada das teorias substituídas. Para provar seu ponto seria necessário contestar $\left(1^{\prime \prime \prime \prime}\right)$. Psillos sugere que a jogada (move) divide et impera

Principia 18(2): 269-290 (2014). 
é baseada na afirmação de que quando uma teoria é abandonada, seus constituintes teóricos, i.e. os mecanismos teóricos e leis que ela postulou, não devem ser rejeitados en bloc. Alguns daqueles constituintes teóricos são inconsistentes com o que agora nós aceitamos e, portanto, devem ser rejeitados. Mas nem todos. Certamente alguns deles ao invés de terem sido abandonados, foram retidos como constituintes essenciais das teorias subsequentes. A jogada (move) divide et impera sugere que se ocorre que constituintes teóricos responsáveis pelo sucesso empírico de teorias outrora abandonadas são aqueles retidos na nossa imagem científica atual, então uma versão substantiva do realismo científico pode ainda ser defendida. (Psillos 1996, p.S308)

Psillos tentará, portanto, mostrar que as teorias substituídas eram aproximadamente verdadeiras em seus aspectos relevantes e que muitos dos termos não referentes da lista de Laudan não eram parte essencial naquelas teorias. Se Psillos mostrar que as partes constituintes responsáveis pelo sucesso de uma teoria são preservadas numa mudança científica, o CER poderia contar com uma formulação resistente à PMI.

O autor reconhece a necessidade de construir um realismo condizente com os dados históricos e, embora não realize um trabalho exaustivo no sentido de excluir qualquer dúvida de que as teorias listadas por Laudan são aproximadamente verdadeiras, Psillos indica como fazê-lo:

O que é requerido para realizar de modo bem-sucedido a jogada (move) divide et impera? A chave para essa questão repousa no estudo cuidadoso da estrutura e do conteúdo de teorias passadas genuinamente bem-sucedidas. O que é necessário são estudos de caso cuidadosos que tentarão:

i) identificar, nas teorias passadas genuinamente bem-sucedidas, os constituintes teóricos que contribuíram para o sucesso daquelas.

ii) mostrar que esses constituintes teóricos, longe de serem caracteristicamente falsos, foram retidos em teorias subsequentes do mesmo domínio. (Psillos 1996, p.S310)

A esperança para o realista permanece porque, segundo Psillos, estudos relevantes mostram que tanto para a teoria do calórico quanto para as teorias do éter do século XIX é possível realizar os passos (i) e (ii). O sucesso da teoria de Carnot, por exemplo, não depende de o calórico ser uma substância material, mas da impossibilidade de um movimento perpétuo. Psillos, para responder a uma possível objeção de que faz um passo ad hoc, ainda considera que os cientistas eminentes estão o tempo todo avaliando quais partes das teorias são realmente responsáveis por seu sucesso, suspeitando de elementos especulativos em demasia e cujo contributo seja duvidoso. Assim, de acordo com Psillos, a prática científica não segue o "tudo ou nada" que, segundo ele, exige o antirrealista.

Principia 18(2): 269-290 (2014). 
Outro desafio que Psillos procura responder é sobre a necessidade de uma teoria da referência, pois dificilmente algum antirrealista aceitaria chamar de aproximadamente verdadeira uma teoria cujos constituintes teóricos não são referentes. Para esse desafio, o autor sugere duas respostas realistas:

$1^{\text {O }}$ Muitos casos de teorias substituídas são aproblemáticos, pois muitos dos termos abandonados simplesmente não eram centrais. A teoria do calor seria paradigmática dessa posição, para Psillos. Segundo o autor, a maioria dos cientistas que trabalhavam com a teoria não se apoiavam no calórico como realidade, mas procuravam derivar leis que regem os fenômenos de calor independentes da assunção sobre tal termo teórico.

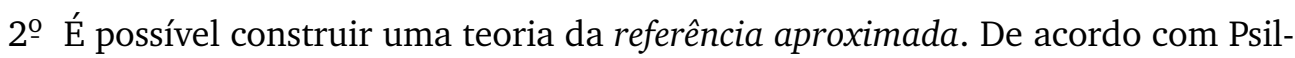
los, quando uma entidade é abandonada, muitas das qualidades (mas não todas) atribuídas a ela vão permanecer de modo aproximado numa entidade $\beta$ atualmente postulada. Embora não haja, de acordo com as teorias correntes, nenhuma entidade com os atributos de $\alpha$, pode muito bem ocorrer que $\beta$ tenha características aproximadas da entidade abandonada e que tais características sejam causalmente responsáveis pelos mesmos fenômenos que $\alpha$ explicava. Nesses casos, que Psillos prefere deixar no campo hipotético, $\alpha$ seria aproximadamente referente.

Assim, a estratégia do divide et impera poderia simplesmente responder à PMI mostrando que ou os termos abandonados não eram centrais ou eram aproximadamente referentes. Embora isso não tenha sido demonstrado, já que Psillos não faz a análise de cada teoria da lista de Laudan, parece um caminho plausível para a defesa do CER. O realismo de Psillos, entretanto, é por ele chamado de uma versão substantiva, capaz de se adaptar e cautelosa quanto à verossimilhança das teorias historicamente relevantes. Diz-nos Psillos:

Se bem-sucedido, eu apenas motivei uma versão substantiva do realismo científico que não é derrotada pela 'indução pessimista': ela sobrevive porque aprendeu a se adaptar, isto é, a ser mais realista em suas aspirações e comprometimentos. Ela sustenta uma conexão explanatória entre sucesso genuíno e verossimilhança, mas aponta que assunções de verossimilhança só se estendem aos constituintes teóricos que essencialmente contribuem para o sucesso das teorias. (Psillos 1996, p.S313)

Como se vê, Psillos não só levou a sério o desafio de Laudan, como reconheceu que os realistas precisam de uma boa teoria da referência. Sua proposta, entretanto, não passa de um esboço que demanda um maior desenvolvimento, seja na análise dos casos históricos levantados pela PMI, seja pela elaboração de uma teoria da referência mais defensável.

Principia 18(2): 269-290 (2014). 
Receio, entretanto, que apesar de supor tal realismo uma filosofia "cautelosa" a manobra divide et impera permite dizer que praticamente qualquer teoria, mesmo aquelas reconhecidamente falsas, seja aproximadamente verdadeira. No sentido exposto por Psillos, poderíamos afirmar que a teoria atômica de Demócrito e Leucipo é aproximadamente verdadeira, pois outras entidades postuladas atualmente pelas teorias de sucesso são consideradas indivisíveis ou respondem pela composição material do mundo físico. A teoria aristotélico-medieval do movimento dos projéteis também poderia ser considerada aproximadamente verdadeira já que a inércia e o atrito da mecânica clássica ocupam o lugar explicativo do impetus medieval e da tendência natural ao repouso de Aristóteles. Uma vez que nem todas as características de uma entidade abandonada precisam estar presentes nas entidades da teoria substituta, a chamada referência aproximada salva talvez qualquer teoria de sucesso não referente do passado. Além disso, não parece que um termo não referente de uma teoria abandonada seja realmente dispensável (ou não central) para o sucesso daquela teoria, pois no contexto teórico em que surge, o poder explanatório de uma teoria depende de todos os seus constituintes. Se fossem desnecessários, não seriam nem postulados. Por exemplo, na hipótese do éter do século XIX, não seria possível explicar como o comportamento da luz era idêntico ao de uma onda sem que um meio possibilitasse sua propagação. Supor que o éter não é central para aquela teoria seria retirar qualquer poder de explicação da mesma. Tampouco consideramos possível afirmar que haja alguma entidade na teoria dos fótons que substitua (via referência aproximada) os atributos do éter sem alargar indesejavelmente o conceito de "verdade aproximada".

Assim, parece que se Psillos acerta em cercar sua posição da acusação de fazer uma suposição ad hoc apelando para a modus operandi dos cientistas atuais que procuram não aceitar ou rejeitar uma teoria em bloco. Talvez seja até possível reduzir a lista de Laudan mostrando como alguns termos não eram centrais nas teorias abandonadas. O mesmo já não é possível dizer sobre a noção de referência aproximada. Assumir essa proposta de teoria da referência é oferecer um conceito vago demais, que salva da acusação de falsidade muitas teorias que talvez nem os realistas mais otimistas estejam dispostos a sustentar como aproximadamente verdadeiras.

A crítica anterior se aplica no caso de a aproximação de Psillos ser correta. O filósofo, entretanto, sofreu também críticas como as de Chang (2003) e de Elsamahi (2005) tanto no que diz respeito ao realismo seletivo quanto em divergências na interpretação da história da teoria do calor.

Chang entende que o caso do calórico é ou irrelevante para a argumentação de Psillos ou favorável ao desafio de Laudan. Em primeiro lugar, Chang afirma que a calorimetria é anterior à teoria do calórico e construída somente em bases fenomenológicas, o que leva a conclusão trivial (proposta por Psillos) de que ela não dependia da existência do calórico para ser bem sucedida. Mas justamente por ser anterior, a 
calorimetria não se mostra um caso exemplar contra Laudan:

Nada na calorimetria realmente depende da teoria do calórico; se esse é o ponto de Psillos, então o ponto está correto. Mas se a calorimetria não era uma parte da teoria do calórico, a preservação de práticas calorimétricas na ciência posterior não existe aqui ou lá quando tentamos ver se o caso do calórico suporta a contenção de Laudan (Chang 2005, p.904)

Outro problema apontado por Chang é sobre a tese de Psillos segundo a qual os cientistas são prudentes em se apoiar sobre entidades teoricamente postuladas e são seletivos sobre as causas do sucesso de suas teorias. As explicações de Laplace dependiam da ontologia pressuposta em sua teoria:

Naquele tempo, a única explicação plausível do calor adiabático era entendê-lo como o desprendimento de calórico de matéria ordinária, causada por compressão mecânica. Como a teoria cinética padrão naquele tempo compreendia calor como vibrações de moléculas em torno de pontos fixos mesmo em gases, ela não poderia dar uma explicação plausível do calor adiabático. (Chang 2003, pp.904-5)

Além dos dois casos anteriores, Chang ainda revisa o sucesso da teoria de Carnot. Para ele Carnot desenvolveu sua teoria sem recorrer à microfísica laplaciana, mesmo quando fez uso da lei adiabática. E até o sucesso da termodinâmica como conhecemos deveu-se a profundas alterações dos conceitos propostos por Carnot por Joule e Kelvin.

Elsamahi (2005) procurará refutar o divide et impera de Psillos tanto na revisão histórica de alguns casos exemplares quanto apelando para as consequências de tal realismo localizado. Não é minha intenção reescrever a aproximação histórica de cada caso estudado pelo autor. Por isso atenho-me a um que parece bastante iluminador do problema enfrentado pelo divide et impera: trata-se da teoria do decaimento beta de Fermi. A teoria postulava a existência de neutrinos que só foi confirmada duas décadas mais tarde. O fato é que a teoria conseguiu sucesso preditivo onde os neutrinos não eram mais que termos teóricos e, segundo Elsamahi, não desempenhavam papel nenhum em tais predições. O que qualquer realista faria era considerar a existência de neutrinos a melhor explicação para a teoria de Fermi ser bem sucedida. Mas um adepto do divide et impera, vivendo na época da elaboração da teoria do decaimento beta, adotaria uma postura cética: o neutrino não seria um termo central para o sucesso da teoria e, tais como na lista de Laudan, poderiam ser dispensados.

O outro problema, de ordem filosófica, ao qual Elsahami se refere é a dispensabilidade das teorias. No caso de o sucesso e o fracasso deverem não à teoria como um todo, mas aos seus constituintes, qual seria o propósito de construir teorias? A unidade teórica estaria ameaçada e os cientistas poderiam se contentar apenas com crenças particulares obtidas de experimentos e leis empíricas:

Principia 18(2): 269-290 (2014). 
Se constituintes individuais de teorias são unidades de crença ou descrença e também blocos definitivos de conhecimento científico, por que precisamos de teorias afinal? Por que cientistas não devem formular e testar crenças individuais sobre o mundo sem assimilar-las em teorias inteiras? Cientistas podem derivar crenças individuais de experimentos e leis empíricas, por exemplo. (Elsahami 2005, p.1357)

Elsahami analisa duas respostas possíveis de realistas seletivos à questão por ele elaborada:

a) Teorias seriam necessárias para que delas pudéssemos derivar algumas verdades aproximadas. Mas nesse caso seu papel seria exclusivamente heurístico.

b) Terias seriam necessárias porque a única maneira de ter uma assunção confirmada é derivá-la de teorias confirmadas. Mas aqui também isso parece uma má explicação: já que uma teoria não é bem sucedida por causa de todos os seus constituintes, não é possível dizer que a confirmação da teoria conte como confirmação de seus constituintes.

Das críticas referidas, caso estejam corretas, conclui-se que a jogada divide et impera não constitui um realismo defensável resistente ao desafio da PMI.

\section{A PMI como desafio cético}

Procuramos mostrar até aqui como algumas críticas à PMI não se sustentam em si mesmas. Foi mencionado neste texto que não consideramos a PMI nem uma indução e nem uma reductio. Se nessa parte final do artigo ficar demonstrado que o desafio de Laudan não deve ser reformulado como um argumento, quer indutivo, quer dedutivo, talvez isso possa tirar de campo qualquer tentativa realista de desqualificar a PMI como falácia.

Primeiramente, tentemos avaliar se a PMI é uma indução. Talvez por influência da "indução desastrosa" de Putnam, muitos realistas leram a lista de Laudan como uma enumeração que poderia ser generalizada. Park (ver 2.1), por exemplo, parece ter feito isso. Se a PMI fosse um caso de generalização, seria um argumento indutivo bastante estranho, como pensa Saatsi:

Devemos notar que o argumento de Laudan é de certa forma um caso atípico de indução. Usualmente a indução é descrita como uma inferência do particular para o geral, e ela tipicamente concerne em estados de casos em tempos futuros de estados de casos em tempos passados. Mas temos visto que a [PMI] não é melhor caracterizada nesses termos. (Saatsi 2005, p.1093)

De fato, Laudan não parece querer afirmar que todas as teorias atuais (ou a maioria delas) são falsas. Na verdade, mesmo que todas as teorias atuais sejam (aproximadamente) verdadeiras, a PMI de Laudan funcionaria como um desafio ao NMA, 
minando a relação entre sucesso e verdade (verossimilhança). Não se trata, portanto, de uma previsão de falsidade das teorias atuais e nem mesmo um argumento probabilístico. Consequentemente, não se trata de uma indução.

Em seguida analisemos se a PMI é uma dedução. Em primeiro lugar remarcamos que as formulações quer de Lewis quer de Mizrahi não fazem justiça ao desafio de Laudan. Se quisermos entender a PMI como reductio teríamos que tomar a formulação $\left(1^{\prime \prime \prime \prime}\right)-\left(4^{\prime \prime \prime \prime}\right)$ que expomos em 2.3. É um argumento dedutivo, sem dúvida, mas um argumento dispensável. O que Laudan questiona é a relação necessária entre sucesso e verossimilhança postulada pelo CER. Enquanto a afirmação de que teorias bem-sucedidas podem não ser referenciais é a única conclusão obtida dedutivamente com as premissas inspiradas pelo artigo de 1981, nenhuma afirmação pode ser feita sobre a verdade (aproximada) das teorias de sucesso correntes. Assim, a reductio não é uma prova de que o realismo sucumbiu. Vejamos a advertência escrita por Laudan sobre as consequências de seu artigo:

É importante se resguardar de uma possível má interpretação desse ensaio.
Nada que eu disse aqui refuta a possibilidade em princípio de uma episte-
mologia realista da ciência. (...) Minha tarefa aqui é mais recordar-nos de
que há uma diferença entre querer acreditar em algo e ter boas razões para
acreditar nisso. Todos nós gostaríamos que o realismo fosse verdadeiro; gos-
taríamos de pensar que a ciência funciona porque tem controlado como as
coisas realmente são. Mas tais assunções não podem ser feitas ainda. (Lau-
dan 1981, p.48)

Como a afirmação 'o sucesso não é indicador confiável da verdade das teorias' pode ser obtida tanto pela reductio como pelo reconhecimento da lista de Laudan, poderíamos até dispensar o argumento como desnecessário face à confirmação histórica da tese do artigo de 1981. Nesse caso, poderíamos afirmar que a verdadeira questão levantada por Laudan não é posta pelo argumento dedutivo, mas pela consequente necessidade de o realismo explicar o sucesso de teorias passadas não referentes de modo a continuar sustentando que a verdade aproximada das teorias atuais é a melhor explicação para seu sucesso.

A nosso ver, a PMI não afirma nem nega a possibilidade de um realismo convergente. Sobre tal ponto é como se Laudan suspendesse o juízo. É nesse sentido que afirmamos ser a PMI um desafio cético. Somente se houvesse uma afirmação de que o CER é um projeto impossível (ou improvável), ou ainda que as teorias correntes bem-sucedidas sejam falsas em seus termos teóricos é que Laudan teria que demonstrar como tal se daria. A verdadeira forma da PMI seria não uma tese, mas uma questão (ou uma série de questões) dirigidas ao CER: como saber se as teorias atuais de sucesso são referentes? Como o sucesso poderia explicar a referência genuína nas teorias atuais se não foi suficiente para sustentar a referência de teorias passadas? Se a melhor explicação para o sucesso é a verdade aproximada das teorias, como 
explicar o sucesso de teorias falsas? Que significa "aproximadamente verdadeira" quando se refere a uma teoria científica?

Questões, sabemos muito bem, não são verdadeiras nem falsas e, portanto não podem ser postas em causa. Na verdade, como um cético, Laudan exige que o realista justifique suas crenças mais caras. Eximir-se de responder a esse questionário porque uma formulação indutiva da PMI parece fraca ou porque uma reductio não presente explicitamente na obra de Laudan não é válida ou ainda porque uma premissa de uma dedução (não defendida no artigo de 1981) pode ser provada falsa não parece ser o caminho mais adequado ao realismo. Talvez aqui, mesmo discordando da teoria da referência aproximada ou do divide et impera, uma lição pode ser aprendida pelo CER com Psillos: o realismo não pode desconsiderar a PMI e, se quiser assumir a verdade aproximada das teorias atuais por causa de seu sucesso preditivo e explicativo, é necessário explicar o sucesso das teorias passadas não referenciais e construir uma boa teoria da referência que delimite melhor o significado de "aproximadamente verdadeiro".

\section{Referências}

Chang, H. 2003. Preservative realism ant its discontents: revisiting caloric. Philosophy of Science 70: 902-12.

Elsamahi, M. 2005. A critique of localized realism. Philosophy of Science 72: 1350-60.

Fahrbach, L. 2011. How the growth of science ends theory change. Synthese 180: 139-55

Laudan, L. 1981. A confutation of convergent realism. Philosophy of Science 49: 19-49.

Leplin, J. 1997. A novel defense of scientific realism. New York: Oxford University Press.

Lewis, P. 2001. Why the Pessimistic Induction Is a Fallacy. Synthese 129: 371-80.

Mizrahi, M. 2013. The pessimistic induction: a bad argument gone too far. Synthese 190: 3209-26.

Oliveira, T. L. T. 2012. O argumento pluralista para o realismo hipotético de Feyerabend. Sapere Aude 3(5): 142-60.

Park, S. 2011. A confutation of pessimistic induction. Journal for General Philosophy of Science 42: $75-84$.

Poincaré, H. 1902[1952]. Science and Hypothesis. New York: Dover. Originally published as La science et l'hypothese. Paris: Flammarion.

Psillos, S. 1996. Scientific realism and the pessimistic induction. Philosophy of science (Proceedings): 306-14.

- 1999. Scientific realism: How science tracks truth. New York: Routledge.

Putnam, H. 1975. Realism in mathematics and elsewhere. In: H. Putnam, Philosophical papers vol. 1. Cambridge University Press.

- 1978. Meaning and the Moral Sciences. London: Routledge.

Russell, B. 1912 [1959]. The problems of philosophy. Oxford: Oxford University Press.

Saatsi, J. T. 2005. On the pessimistic induction and two fallacies. Philosophy of Science 72: 1088-98.

Principia 18(2): 269-290 (2014). 
van Fraassen, B. 1980. The Scientific Image. Oxford: Oxford University Press.

Wray, K. B. 2013. The pessimistic induction and the exponencial growth of science reassessed. Syntese 190: 4321-30.

Tiago Luís TeiXeira de Oliveira Professor do Colégio Pedro II - Campus Niterói-RJ

Doutorando em Filosofia pela UFMG tiagoluis@ymail.com

Resumo. O presente artigo tem por objetivo descrever a metaindução pessimista (PMI) e responder a alguns autores realistas que consideram a PMI uma falácia. A maioria dessas tentativas são más interpretações das ideias de Laudan, falhando o alvo. Este trabalho pretende mostrar que a PMI não é uma indução e nem uma reductio, mas um desafio cético. Se isso estiver correto, então a PMI não pode ser uma falácia e o realismo não pode escapar da tarefa de explicar porque o sucesso é um bom indicador para a verossimilhança das teorias correntes.

Palavras-chave: Indução pessimista; realismo; antirrealismo; Laudan; Psillos.

\section{Notas}

${ }^{1}$ Embora o conhecimento de como os teóricos atuam ao criar novas hipóteses possa ser útil para entender a lógica da descoberta (ou a psicologia da descoberta, o que seria mais preciso para muitos filósofos da ciência), em nada esse conhecimento autorizaria acreditar nas entidades inobserváveis postuladas pela teoria em desenvolvimento. Como veremos no decorrer do trabalho, nem mesmo em relação teorias bastante maduras isso seria prudente. ${ }^{2}$ A abdução ou inferência pela melhor explicação (IBE) é um argumento indutivo que Peirce (1839-1914) sugeriu estar por trás do método científico, especificamente no que trata de escolha dentre explicações alternativas. Formalmente poderia ser pensada assim:

$$
\begin{aligned}
& \left(A \rightarrow B_{1}\right) \wedge\left(A \rightarrow B_{2}\right) \wedge \ldots \wedge\left(A \rightarrow B_{n}\right) \\
& B_{1} \wedge B_{2} \wedge \ldots \wedge B_{n-1} \\
& \therefore \quad A
\end{aligned}
$$

Para esse modo de raciocinar, a ocorrência de uma série de eventos $\left(B_{1} \ldots B_{n-1}\right)$ que seriam implicados pelo evento $A$ conta a favor de $A$ como melhor explicação dessa série. Dentre as várias explicações para o carro $\left(B_{1}\right)$, o jardim $\left(B_{2}\right)$ e o telhado $\left(B_{3}\right)$ estarem molhados, a melhor parece ser a chuva $(A)$, muito embora não haja garantias de que cada evento não tenha causas distintas. Ver Zilhão, António. Abdução in: Branquinho, João; Murcho, Desidério; Gomes, Nelson Gonçalves. Enciclopédia de termos lógico-filosóficos. São Paulo: Martins Fontes, 2006, p.9-11. Para os realistas, o sucesso de teorias maduras em explicar fenômenos, fazer previsões acuradas, permitir a construção de artefatos tecnológicos eficientes e não estar em conflito com outras teorias bem sucedidas tem como melhor explicação que essas teorias são aproximadamente verdadeiras e seus termos teóricos genuinamente referem. Para ver uma severa crítica antirrealista à tal tipo de inferência cf. van Fraassen, B.C. A imagem científica. Trad. Luiz Henrique de Araújo Dutra. São Paulo: UNESP, 2007.

Principia 18(2): 269-290 (2014). 
${ }^{3}$ Carnap em 1954 publicou The methodological character of theoretical concepts, no qual fornece as bases para essa concepção de que as teorias que formulamos são, no máximo, ferramentas úteis na sistematização e previsão dos dados empíricos. Segundo o filósofo, é possível diferenciar a linguagem teórica de uma linguagem observacional, sendo possível traduzir os termos introduzidos pelas teorias numa série de descrições empiricamente observáveis. Tal interpretação esvazia o caráter ontológico que comumente se atribui aos termos inobserváveis, substituindo-os por uma linguagem observacional essa sim passível de significação. Isso significa que para instrumentalistas como Carnap, as teorias só são verdadeiras ou falsas no que diz respeito ao mundo observável.

${ }^{4}$ Em relação ao argumento de Putnam formulado por Lewis, concordarei com a posição de Mizrahi (2013) para quem é simplesmente um argumento inválido. A postura de Mizrahi será analisada mais adiante (2.3).

${ }^{5}$ Laudan, no artigo de 1981, não intenta mais do que mostrar que os realistas estavam baseando-se no desejo de que o realismo seja verdadeiro e, como se pode ler na conclusão do artigo em questão e também na citação contida na parte 3 deste trabalho, o autor não pretendeu derrubar o realismo, mas chamá-lo a se fundamentar em bases mais sólidas. Isso não significa que Laudan não tenha tentado alguma alternativa ao realismo e mesmo que ele seja apenas um cético. No famoso livro de sua autoria, Progress and its problems (publicado pela primeira vez em 1978), Laudan afirma categoricamente que o realismo não tem papel algum na resolução de problemas empíricos. Veja-se, por exemplo o seguinte trecho:

Seja qual for o papel que a verdade desempenhe no empreendimento científico (...), não precisamos, e os cientistas em geral não o fazem, considerar questões de verdade e falsidade ao determinar se uma teoria resolve ou não um problema empírico.

A teoria de Ptolomeu sobre os epiciclos resolveu o problema do movimento retrógrado dos planetas, independente de aceitarmos ou não a verdade da astronomia dos epiciclos. Da mesma maneira, a teoria ondulatória da luz de Thomas Young — seja ela verdadeira ou falsa — resolveu o problema da dispersão da luz. A teoria da oxidação de Lavoisier, seja qual for seu estatuto de verdade, resolveu o problema de por que o ferro fica mais pesado depois de aquecido. Em geral, pode-se considerar que qualquer teoria, T, resolva um problema empírico, se funcionar (significativamente) em qualquer esquema de inferência cuja conclusão for uma declaração do problema. (Laudan 2010, pp.35-6)

${ }^{6}$ Consiste em transformar a posição que se quer atacar numa caricatura (um espantalho) de modo que torne impossível ao leitor concordar com a mesma.

${ }^{7}$ É importante ressaltar que essa crítica ao argumento de Park não é especificamente uma resposta antirrealista. Ela se insere num contexto filosófico mais geral, em discussões da metafísica e da filosofia da lógica. Uma teoria coerentista da verdade supõe que uma crença é verdadeira se e somente se ela é consistente com as demais crenças tidas por verdadeiras ou se ela é acarretada pelas demais crenças tidas por verdadeiras. Como o acessível e já clássico The problems of philosophy de Russell (1912) muito bem explica, é possível criar teorias bastante coerentes com o corpo de crenças que já possuímos (por exemplo sobre o passado) e, no entanto, bastante improváveis, como o gênio maligno de Descartes. Todo o nosso conhecimento sobre o mundo e sobre a matemática são coerentes com um ser poderoso que

Principia 18(2): 269-290 (2014). 
manipula nossa mente. A coerência, por si só, não sustentaria a verdade da existência de um ente como o sugerido por Descartes.

${ }^{8}$ Ver meu artigo $O$ argumento pluralista em favor do realismo hipotético de Feyerabend (2012), de modo especial o caso do movimento browniano (p.152 ss). Feyerabend mostra como alguns casos de mudanças teóricas ocorreram sem a existência de uma experiência refutadora. Nesses casos, entretanto, observou-se uma mudança na ontologia. O desenvolvimento dessas novas teorias seria impossível se os cientistas tivessem a consistência como critério irrevogável.

Principia 18(2): 269-290 (2014). 